\title{
Re: Deep Neuromuscular Blockade Improves Surgical Conditions During Low-Pressure Pneumoperitoneum Laparoscopic Donor Nephrectomy
}

Özdemir-van Brunschot DMD1, Braat AE2, van der Jagt MFP1, Scheffer GJ3, Martini CH4, Langenhuijsen JF5, Dam RE2, Huurman VA2, Lam D2, d'Ancona FC5, Dahan A4, Warlé MC1

${ }^{1}$ Radboud University Medical Centre, Department of Surgery, Division of Vascular and Transplant Surgery, Nijmegen, The Netherlands 2Leiden University Medical Center, Department of Surgery, Leiden, The Netherlands

${ }^{3}$ Radboud University Medical Centre, Department of Anesthesiology, Nijmegen, The Netherlands

${ }^{4}$ Leiden University Medical Centre, Department of Anesthesiology, Nijmegen, The Netherlands

${ }^{5}$ Radboud University Medical Centre, Department of Urology, Nijmegen, The Netherlands

Surg Endosc 2017. doi: 10.1007/s00464-017-5670-2.

\section{EDITORIAL COMMENT}

In this small blinded randomized controlled multicenter trial, the authors have evaluated the effect of deep neuromuscular blockade (NMB) on surgical conditions during-low pressure pneumoperitoneum (PNP) laparoscopic donor nephrectomy. Previous evidence supports that low-pressure PNP $(6 \mathrm{mmHg}$ ) reduces post-operative pain, but sometimes may restrain visibility and surgical access. By applying deep NMB authors were able to demonstrate lower post-operative opiate requirement besides improvement in surgical conditions. Although not significant, insufflation pressures were lower in the deep NMB group. In four patients in the moderate NMB group, major intraoperative complications occurred in whom two required conversion to open procedure have had occurred. Given the relatively high incidence of intraoperative complications and conversions to open donor nephrectomy, the use low-pressure PNP with moderate NMB may compromise safety during surgery.

Yarkın Kamil Yakupoğlu, MD

๑Copyright 2017 by the Association of Urological Surgery / Journal of Urological Surgery published by Galenos Publishing House. 